\title{
La disección aórtica continúa siendo una entidad de elevada mortalidad y un desafío diagnóstico y terapéutico
}

The International Registry of acute aortic dissection (IRAD). New insights into an old disease.

Hagan PG, Nienaber CA, Isselbacher EM et al. JAMA. 2000; 283: 897-903.

\section{Objetivo}

Caracterizar la forma de presentación, el manejo terapéutico y la evolución de la disección aórtica aguda.

\section{Diseño}

Estudio prospectivo observacional. Los pacientes fueron incluidos en forma consecutiva desde enero de 1996 a diciembre de 1998.

\section{Lugar}

Estudio multicéntrico con participación de 12 centros de referencia, 6 de Europa, 4 de Estados Unidos y 2 de Asia.

\section{Pacientes}

Se incorporaron 464 pacientes, 289 (62.3\%) con disección tipo A (compromiso de aorta ascendente) y 175 tipo B (aorta transversal y descendente). El promedio de edad fue de 63.1 años y el $65 \%$ de sexo masculino.

\section{Medición de resultados principales}

Fueron analizadas la forma de presentación, el examen físico, la conducta y la mortalidad.

\section{Resultados}

El dolor de aparición súbita fue la presentación más frecuente
(84.8\%), el dolor de carácter agudo fue más frecuente que el desgarrante ( 65 versus $50 \%$ ), sólo un $49 \%$ se encontraban hipertensos al ingreso aunque la mayoría (72\%) tenían antecedentes de hipertensión arterial. La insuficiencia aórtica se detectó en $31.6 \%$ y el déficit de pulsos en $15 \%$ de los pacientes. Con respecto a la radiografía de tórax la mayoría eran anormales, pero un $21.3 \%$ no presentaban ensanchamiento del mediastino ni deformidad del contorno aórtico.

El ECG de ingreso no fue útil, en la mayoría se observaron datos inespecíficos y en 31\% el ECG fue normal. El método diagnóstico más utilizado fue la tomografía computada.

La mortalidad global de los pacientes fue $27.4 \%$, en la disección tipo A intervenidos quirúrgicamente $26 \%$ y en los no operados $58 \%$. La mortalidad en la disección tipo B operada fue $31.4 \%$ y en los no intervenidos $10.7 \%$.

\section{Conclusiones}

La disección aórtica tiene una presentación polimorfa y sus hallazgos clásicos pueden éstar ausentes. Para realizar el diagnóstico se requiere un alto grado de sospecha. A pesar de los avances diagnósticos y terapéuticos su mortalidad es elevada. Estos datos sugieren que es necesario mejorar la prevención, el diagnóstico y el tratamiento de esta entidad.

\section{COMENTARIO}

El impacto de las nuevas técnicas diagnósticas y terapéuticas sobre la evolución de la disección aórtica en una serie numerosa de pacientes no estaba valorado hasta el desarrollo de este registro internacional.

Aunque los resultados seguramente no sean representativos de la conducta ni de la evolución de esta patología en la comunidad (ya que sólo participaron en el registro 12 centros cardioquirúrgicos de referencia, y por una cuestión de diseño sólo se incluyeron los pacientes que ingresaban vivos al hospital), la información clínica que brinda es muy importante. Merece destacarse que algunos datos del examen físico descriptos como patognomónicos (muy específicos) son poco sensibles, como el caso de la ausencia de pulsos y la regurgitación aórtica; lo mismo ocurre con el sindrome de Marfan que se observó en menos del $5 \%$ de los casos. Para la confirmación diagnóstica el estudio inicialmente más usado fue la tomografía, especialmente para los disecantes B. Probablemente la utilización relativa de métodos diagnósticos haya variado en los últimos años por la difusión del ecordiograma transesofágico. La radiografía de torax mostró datos sugerentes de patología aórtica en un $78.7 \%$, pero es importante considerar que en 1 de cada 5 pacientes fue normal. Con respecto a la evolución hospitalaria los pacientes con disección tipo A no operados tuvieron más del doble de mortalidad que los intervenidos; esto se explica por la elevada mortalidad durante la fase aguda de los no operados y porque se tomó la conducta no quirúrgica en pacientes de alto riesgo como aquellos portadores de comorbilidades, edad avanzada, etc. En cambio los pacientes con disección tipo B operados triplicaron la mortalidad de los no operados, estos resultados se explican porque la conducta habitual es operar las disecciones B recién cuando aparecen complicaciones. Este registro no refleja el impacto de nuevas técnicas como la colocación percutánea de una prótesis endovascular en la disección de aorta descendente, que promete ser un procedimiento de menor riesgo y buenos resultados.

No hay duda que se ha avanzado, la disección aórtica ha pasado de ser una entidad de hallazgo post mortem a ser una entidad que se puede diagnosticar y modificar la evolución de muchos de los casos. También es claro que aún constituye una patología de alta mortalidad. Más allá de los avances farmacológicos y de los procedimientos quirúrgicos o percutáneos, la prevención en poblaciones de riesgo (hipertensos, Marfán) y el mantener un alto índice de sospecha diagnóstica en las áreas de emergencia son medidas ineludibles.

\section{Dr. César A. Belziti}

Unidad de Cuidados Intensivos Cardiológicos. Instituto del Corazón. Hospital Italiano de Buenos Aires.

\section{Referencias}

